\title{
Temporal pattern in segmental motions of the foot in healthy senile adults: comparison between young and senile healthy adults
}

Sang Gyo Seo ${ }^{1 *}$, Dong Yeon Lee ${ }^{1}$, Ji-Beom Kim¹, Seong Hyun Kim', Hye Sun Park', Hyo Jeong Yoo', Sung Ju Kim² , Jihyeung Kim ${ }^{3}$, Kyoung Min Lee ${ }^{4}$, Chin Youb Chung ${ }^{4}$, In Ho Choi ${ }^{1}$

From 4th Congress of the International Foot and Ankle Biomechanics (i-FAB) Community

Busan, Korea. 8-11 April 2014

The incidence of foot and ankle disease increases as the age increases [1,2]. However, there was no report about differences of foot motion between senile person and young adults. The purpose of this study is to analyze distinctions according to age in segmental foot motion using 3D multifoot model from healthy senior and young adults.

One hundred senile (50 males, 50 females) and young adults ( 50 males, 50 females) were tested by 3D multifoot model with 15 -markers. The cadence, speed, stride length, step width, step time, and stance phase were analyzed. The maximum and minimal values and motions of 3-planes of hallux, forefoot, hindfoot, and arch were compared between senile and young adults.
The cadence, speed, stride length, and step width were lower in senior. The stance phase was longer (Table1). In female, sagittal motion of all segment were more limited and hindfoot was more unstable in senior (Figure 1). In male, sagittal motion of hallux and forefoot were lower in senior (Figure 2). Hallux valgus of male and female was more severe in senior during gait. Arch height was no difference (Figure 3). In 3D foot gait analysis, the differences between senior and young adults were apparent. In summary, foot motion in senior had limited range of motion during gait. And hallux valgus in senior was more severe. But arch height was not diminished. The understanding about changes of foot segmental motion

Table 1 Basic gait parameters in senile adults

\begin{tabular}{llll}
\hline & Male $($ mean \pm SD) & Female $($ mean \pm SD) & $p$-value \\
\hline Cadence $(\mathrm{cm})$ & $109.3 \pm 6.6$ & $114.6 \pm 6.9$ & $<0.001$ \\
Speed $(\mathrm{cm} / \mathrm{sec})$ & $114.0 \pm 9.2$ & $111.5 \pm 7.9$ & 0.147 \\
Stride length $(\mathrm{cm})$ & $124.5 \pm 7.3$ & $116.3 \pm 7.4$ & $<0.001$ \\
Step width $(\mathrm{cm})$ & $62.4 \pm 4.5$ & $58.3 \pm 4.1$ & $<0.001$ \\
Step time (sec) & $0.55 \pm 0.04$ & $0.53 \pm 0.03$ & $<0.001$ \\
Proportion of stance phase (\%) & $61.1 \pm 1.1$ & $60.6 \pm 1.1$ & 0.046 \\
\hline
\end{tabular}

\footnotetext{
* Correspondence: sporter99@naver.com

'Department of Orthopedic Surgery, Seoul National University Hospital,

Seoul, Korea

Full list of author information is available at the end of the article
} 


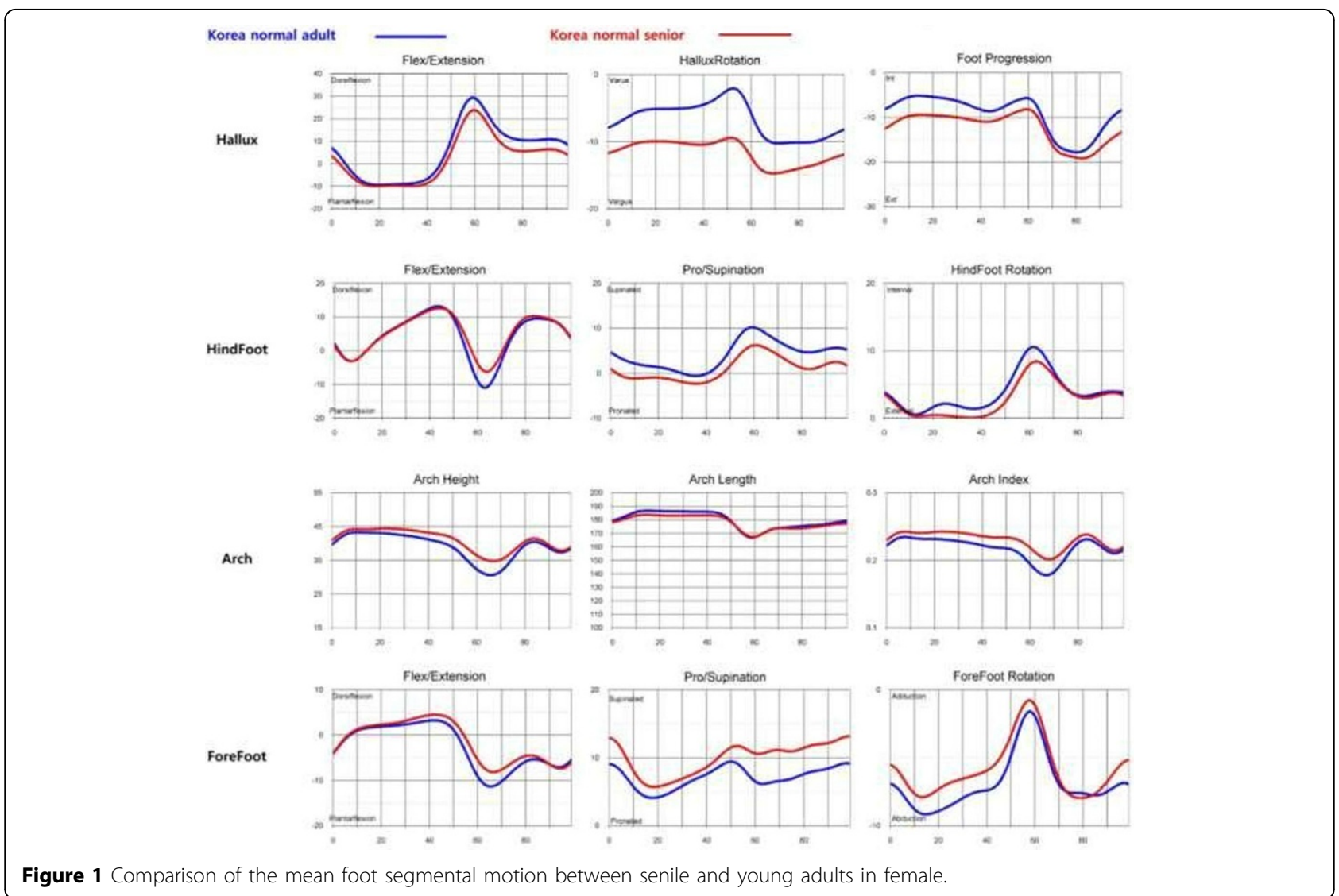

Figure 1 Comparison of the mean foot segmental motion between senile and young adults in female.

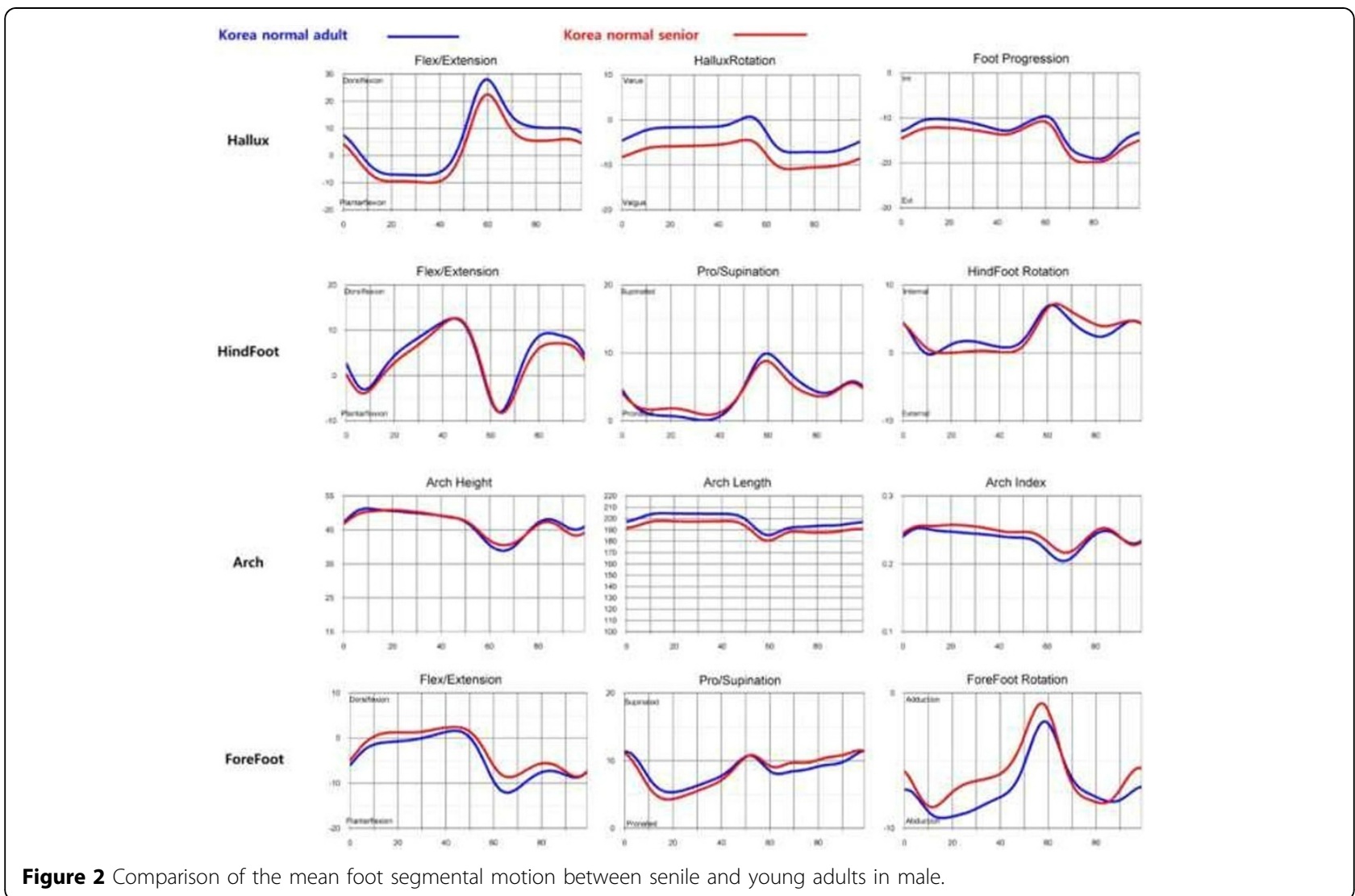

Figure $\mathbf{2}$ Comparison of the mean foot segmental motion between senile and young adults in male. 


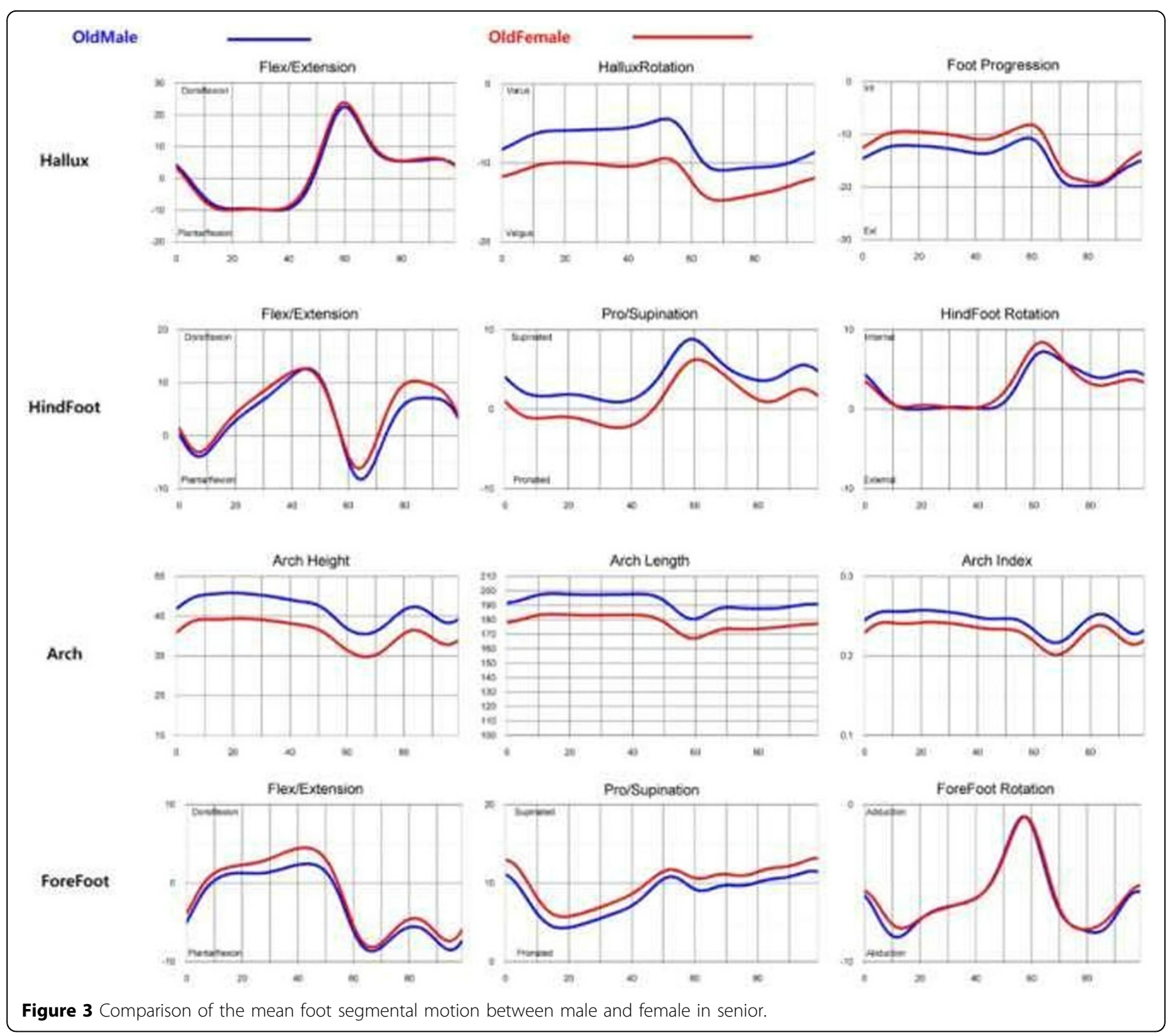

depending on age will suggest more correct approach in degenerative foot and ankle disease.

\section{Authors' details}

'Department of Orthopedic Surgery, Seoul National University Hospital, Seoul, Korea. ${ }^{2}$ Department of statistics, Korea University, Seoul, Korea. ${ }^{3}$ Department of Orthopedic Surgery, Seoul National University Boramae Medical Center, Seoul, Korea. ${ }^{4}$ Department of Orthopedic Surgery, Seoul National University Bundang Hospital, Seongnam, Korea.

\section{Published: 8 April 2014}

\section{References}

1. Ostrosky KM, VanSwearingen JM, Burdett RG, Gee Z: A comparison of gait characteristics in young and old subjects. Phys Ther 1994, 74:637-644, discussion 644-636.

2. Lee JH, Chun MH, Jang DH, Ahn JS, Yoo JY: A comparison of young and old using three-dimensional motion analyses of gait, sit-to-stand and upper extremity performance. Aging Clin Exp Res 2007, 19:451-456.
doi:10.1186/1757-1146-7-S1-A76

Cite this article as: Seo et al: Temporal pattern in segmental motions of the foot in healthy senile adults: comparison between young and senile healthy adults. Journal of Foot and Ankle Research 2014 7(Suppl 1):A76.

\section{Submit your next manuscript to BioMed Central and take full advantage of:}

- Convenient online submission

- Thorough peer review

- No space constraints or color figure charges

- Immediate publication on acceptance

- Inclusion in PubMed, CAS, Scopus and Google Scholar

- Research which is freely available for redistribution 